\title{
PEG and PEG-peptide based doxorubicin delivery systems containing hydrazone bond
}

\author{
Beste Balci ${ }^{1}$ • Ayben Top ${ }^{1}$ (I) \\ Received: 18 October 2017 / Accepted: 20 March 2018 \\ (C) Springer Science+Business Media B.V., part of Springer Nature 2018
}

\begin{abstract}
mPEG and mPEG-peptide based drug delivery systems were prepared by conjugating doxorubicin (DOX) to these carrier molecules via hydrazone bond. The peptide, AT1, with a sequence of $\mathrm{CG}_{3} \mathrm{H}_{6} \mathrm{G}_{3} \mathrm{E}$ served as $\mathrm{mPEG}$ and doxorubicin attachment site. Histidines were incorporated to the sequence to improve $\mathrm{pH}$ responsiveness of the carrier molecule. Hydrodynamic diameters (mean sizes) of mPEG-based drug delivery system (mPEG-HYD-DOX) were measured as $9 \pm 0.5$ and $7 \pm 0.5 \mathrm{~nm}$ at $\mathrm{pH} 7.4$ and $\mathrm{pH}$ 5.0, respectively. Mean size of the aggregates of the peptide containing drug delivery system, mPEG-AT1-DOX, was determined as $12 \pm 2 \mathrm{~nm}$ at neutral $\mathrm{pH}$. At $\mathrm{pH} 5.0$, on the other hand, mPEG-AT1-DOX exhibited a size distribution between 20 and $100 \mathrm{~nm}$ centered at about $40 \mathrm{~nm}$. Comparison of \% DOX release values of the drug delivery systems obtained at $\mathrm{pH} 7.4$ and pH 5.0 indicated that mPEG-AT1-DOX has enhanced $\mathrm{pH}$ sensitivity. DOX equivalent absolute $\mathrm{IC}_{50}$ values were obtained as $0.96 \pm 0.51,21.9 \pm 5.9$, and $5.55 \pm 0.75 \mu \mathrm{g} / \mathrm{mL}$ for free DOX, mPEG-HYD-DOX, and mPEG-AT1-DOX, respectively. Considering more pronounced $\mathrm{pH}$ sensitivity and cytotoxicity of mPEG-AT1-DOX, the use of both $\mathrm{pH}$ responsive functional groups and acid cleavable chemical bond between the carrier molecule and drug can be a promising approach in the design of drug delivery systems for cancer therapy.
\end{abstract}

Keywords $\mathrm{pH}$ responsive drug delivery system $\cdot$ Doxorubicin $\cdot$ Hydrazone bond $\cdot$ PEG $\cdot$ Peptide $\cdot$ Histidine

\section{Introduction}

$\mathrm{pH}$ responsive drug delivery systems (DDS) have been received increasing interest in recent years. Especially in cancer treatment, $\mathrm{pH}$ programmed fast release of antitumor drug has been proposed to increase therapeutic activity of the drug and to overcome the multidrug resistance (MDR) problem of cancer cells [1-7]. Correlation between fast release of the drug and its cytotoxic effect was demonstrated by comparing the \% viability of MDA-MB-231 human breast adenocarcinoma cells exposed to free paclitaxel and paclitaxel loaded nanoparticles of poly(ethylene oxide) (PEO)-modified poly $(\beta$-amino ester) (PbAE) and PEO-modified poly (E-caprolactone) (PCL).

Electronic supplementary material The online version of this article (https://doi.org/10.1007/s10965-018-1506-6) contains supplementary material, which is available to authorized users.

Ayben Top

aybentop@iyte.edu.tr

1 Department of Chemical Engineering, İzmir Institute of Technology, Urla, 35430 İzmir, Turkey
It was shown that at high paclitaxel concentrations, $\mathrm{pH}$ responsive $\mathrm{PEO}-\mathrm{PbAE}$ based paclitaxel carrier system exhibited superior antitumor activity than free paclitaxel and PEO-PCLpaclitaxel system [8]. Additionally, in vitro and in vivo evaluations revealed that $\mathrm{pH}$ sensitive micelles decorated with folate molecules suppressed both sensitive and MDR tumors of MCF-7 remarkably [1].

It was reported that cytoplasmic $\mathrm{pH}$ around 7.2, drops to $\sim 6$ in endosomes, and reaches to $\sim 5$ in lysosomes of drug sensitive tumor cells $[4,9]$. $\mathrm{pH}$ responsive antitumor drug delivery systems exploit the $\mathrm{pH}$ gradient in the endocytic pathway to facilitate fast accumulation of the drugs by dissolution or collapse of the nanoparticles in acidic environment of these organelles [2]. $\mathrm{pH}$ responsiveness can be imparted to the drug delivery system by incorporating $\mathrm{pH}$ sensitive functional groups into the carrier molecules or by attaching antitumor drug to the delivery system via an acid labile chemical bond. For the former case, $\mathrm{pH}$ sensitive functional group can be ionizable or acid degradable and drug can be attached to the carrier system via intermolecular attraction forces. Histidine [1, 10-12], N,N-dialkylaminoethyl methacrylates (DEA) [2], $\beta$-amino esters $[8,13]$, and $2-((((5-$-methyl-2- $(2,4,6-$ 
trimethoxyphenyl)-1,3-dioxan-5-yl)methoxy)carbonyl) amino) ethyl methacrylate (TTAMA) [14] are a few examples of the monomers used to synthesize carrier molecules where $\mathrm{pH}$ responsiveness is achieved by protonation/deprotonation of ionizable building blocks. Acid degradable ketals $[15,16]$, acetals $[17,18]$, and hydrazone [19] functional groups in the backbone of the polymers or copolymers cause disintegration of the polymer and, hence, accelerate release of the drug at acidic conditions. Acid cleavable hydrazone [20-24], acetal [25], and cisaconityl [26] bonds have also been used for covalent conjugation of antitumor drugs to the drug delivery systems.

Even designed to be $\mathrm{pH}$ responsive, one of the possible concerns of the drug delivery systems where drug molecules are hold via intermolecular interactions is considerable release of the cargo at physiological $\mathrm{pH}$. Drug release at neutral $\mathrm{pH}$ can be minimized by chemically attaching the drug to the carrier molecule. However, most of these systems exhibited much slower release at acidic conditions as well compared to their counterparts.

In this study, it was aimed to evaluate the performance of a $\mathrm{pH}$ responsive drug delivery system containing both $\mathrm{pH}$ responsive functional groups and acid cleavable chemical bond between drug and carrier molecule. For this reason, mPEG and mPEG-peptide based drug delivery systems were obtained by covalently attaching DOX to the carrier molecules using acid cleavable hydrazone bond. In these DDSs, PEG was used as a hydrophilic block to increase solubility and blood circulation time of the DDSs during the transport. The designed peptide containing histidines were used to impart additional $\mathrm{pH}$ responsiveness to the carrier molecule. Peptide-free drug delivery system, mPEG-HYD-DOX, was synthesized as a control drug delivery system. Purity of the carrier molecules were assessed. Size distribution, stability, drug release and cytotoxic properties of the DOX-conjugated molecules were investigated.

\section{Materials and methods}

\section{Materials}

Methoxypolyethylene glycol-propionic acid (mPEG$\mathrm{COOH} ; \mathrm{MW}=5000 \mathrm{~g} / \mathrm{mol}, \geq 80 \% \mathrm{COOH}$ functionality), methoxypolyethylene glycol maleimide (mPEG-MAL; $\mathrm{MW}=5000 \mathrm{~g} / \mathrm{mol}, \geq 90 \%$ maleimide functionality), adipic acid dihydrazide (AADH), dimethyl sulfoxide (DMSO), and diethyl ether (DEE) were purchased from SigmaAldrich. (3-Dimethylaminopropyl)-N'-ethylcarbodiimide hydrochloride (EDC. $\mathrm{HCl}$ ) and N-hydroxysuccinimide (NHS) were obtained from P3 Biosystems and Alfa Aesar, respectively. Synthesis grade trifluoroacetic acid (TFA; Merck) and doxorubicin hydrochloride (Medkoo Biosciences) were used for the drug conjugation reactions.
For the peptide synthesis, Rink amide MBHA resin, FmocHis-Trt-OH, Fmoc-Gly-OH, Fmoc-Cys-Trt-OH, FmocGlu-(OtBu)-OH (NovaBiochem), N,N, $\mathrm{N}^{\prime}, \mathrm{N}^{\prime}$-tetramethylO-(1H-benzotriazol-1-yl)uronium hexafluorophosphate (HBTU), hydroxybenzotriazole (HOBt) purchased from P3 Biosystems, dimethyl formamide (DMF), 4-methylmorpholine (NMM), dichloromethane (DCM) obtained from SigmaAldrich, and piperidine (Acros) were used. Triisopropyl silane (TIS; Sigma-Aldrich) and 1,3-dimethoxybenzene (DMB; Sigma-Aldrich) were employed in the cleavage reactions.

Sodium phosphate monobasic, sodium chloride, sodium hydroxide (Sigma-Aldrich), imidazole (Fluka), anhydrous 4morpholineethanesulfonic acid (MES; AppliChem), acetic acid and hydrochloric acid (Merck) were used in the preparation of buffers. HisPur Ni-NTA (Thermo Fisher Scientific) and Sephadex LH-20 (GE Healthcare) resins were employed in the affinity and gel permeation chromatography (GPC), respectively. SnakeSkin dialysis tubing (MW $3.5 \mathrm{kDa}$ ) purchased from Thermo Fisher Scientific was utilized in dialysis and drug release experiments.

Sinapic acid, FTIR grade potassium bromide (SigmaAldrich) and deuterium oxide $\left(\mathrm{D}_{2} \mathrm{O}\right.$; Merck) were used in MALDI-TOF, FTIR and NMR spectroscopy sample preparations, respectively.

Gentamycin sulfate, European grade fetal bovine serum (FBS), trypsin-EDTA solution C and $0.5 \%$ trypan blue solution were purchased from Biological Industries. RPMI-1640 with Lglutamine and 3-(4,5-dimethylthiazol-2-yl)-2,5-diphenyltetrazolium bromide (MTT) were obtained from Sigma-Aldrich and Amresco, respectively. All the chemicals and solvents were used without purification.

\section{Synthesis of methoxypoly(ethylene glycol) -hydrazone-doxorubicin (mPEG- HYD-DOX) conjugate}

Model anticancer drug, doxorubicin, was conjugated to the carrier molecule by following two steps:

- conversion of carboxylic acid groups of mPEG into hydrazide groups

- attachment of doxorubicin to hydrazide functionalized mPEG via hydrazone bond.

Hydrazide form of mPEG denoted as mPEG-HYD was prepared using EDC coupling reaction with AADH in the presence of NHS as given in Fig. 1. In a typical reaction, 3 mmol AADH was dissolved in $10 \mathrm{~mL}$ PBS buffer $(100 \mathrm{mM}$ sodium phosphate containing $150 \mathrm{mM} \mathrm{NaCl}$ ) at $\mathrm{pH} 7.4$ by sonicating at $40-45{ }^{\circ} \mathrm{C}$ (Solution 1). In a separate vial, $50 \mathrm{mg}(\sim 0.01 \mathrm{mmol}) \mathrm{mPEG}-$ propionic acid, $1 \mathrm{mmol} \mathrm{EDC} . \mathrm{HCl}$, and $0.4 \mathrm{mmol}$ NHS were dissolved in $6 \mathrm{~mL} 25 \mathrm{mM}$ MES buffer containing $150 \mathrm{mM}$ $\mathrm{NaCl}$ at $\mathrm{pH} 6.0$ (Solution 2). Next, the solution 2 was stirred at room temperature for $15 \mathrm{~min}$, and it was added onto the solution 
Fig. 1 Reaction scheme of mPEG-HYD-DOX

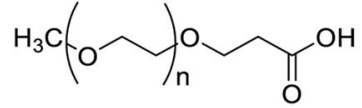

mPEG-propionic acid

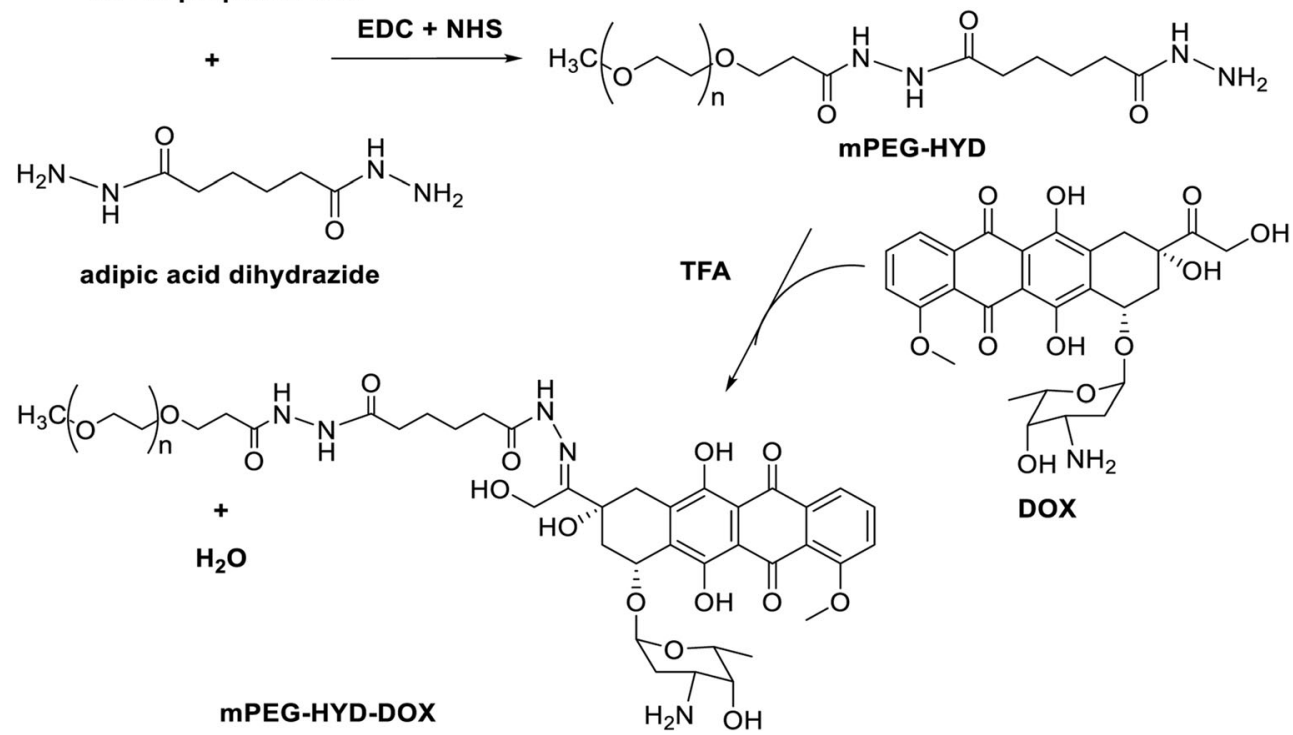

1 dropwise. After that, $\mathrm{pH}$ of the combined solution was adjusted to 7.4 and the reaction was allowed to proceed overnight at $30{ }^{\circ} \mathrm{C}$. To isolate mPEG compounds, the reaction mixture was dialyzed against $100 \mathrm{mM}$ phosphate buffer containing $150 \mathrm{mM}$ $\mathrm{NaCl}$ at neutral conditions followed by against deionized water to remove excess buffer components in addition to remaining small molecular weight excess reactants and by-products. Afterwards, the solution was freeze dried and the product obtained was stored at $-20^{\circ} \mathrm{C}$. Yield of the final product (mixture of mPEG-propionic acid and mPEG-hydrazide) was obtained as 75 $\pm 5 \%$. Hydrazide functionalization was determined as $54 \pm 1 \%$ using ${ }^{1} \mathrm{H}$ NMR. No further purification was applied prior to DOX conjugation.

Ketone group of DOX was conjugated to the hydrazide of mPEG-HYD via the formation of acid cleavable hydrazone bond to obtain the final drug delivery system. DOX conjugation reaction given in Fig. 1 was performed in DMSO $(1 \mathrm{~mL}$ DMSO: 5 mg mPEG-hydrazide) using TFA (\% 2 by volume) as a catalyst at $30{ }^{\circ} \mathrm{C}$ for 3 days by protecting the reaction mixture from light. In these reactions, DOX:mPEG-HYD ratio was used as $\sim 6.8: 1$ in terms of molar basis. After the reaction was completed, the reaction mixture was precipitated over cold DEE and centrifuged to obtain mainly mPEG-DOX conjugates. The supernatant corresponds to some portion of free DOX as depicted from orange color. Residual DEE in the conjugates was removed by drying in a fume hood for a few hours and the dried conjugates were resuspended in DMSO. Gel permeation chromatography was applied to remove remaining free DOX in the conjugates using Sephadex LH-20 resin in DMSO. Then, isolated conjugates (eluted first with red color) were precipitated onto cold DEE to get rid of
DMSO. After drying of the conjugates in a fume hood, they were dissolved in deionized water, freeze dried and stored at $20{ }^{\circ} \mathrm{C}$ (Yield $=65 \pm 3 \%$ ).

\section{Synthesis of methoxypolyethylene glycol-peptide-hydrazone-doxorubicin (mPEG-AT1-DOX) conjugate}

mPEG-peptide-DOX conjugate system was prepared using four steps:

- Peptide synthesis

- Conjugation of mPEG and peptide

- Synthesis of hydrazide form of the mPEG-peptide

- Attachment of the drug

The peptide, denoted as AT1 with a sequence of $\mathrm{CG}_{3} \mathrm{H}_{6} \mathrm{G}_{3} \mathrm{E}$ was synthesized by employing Fmoc strategy on a Rink amide MBHA resin $(0.66 \mathrm{mmol} / \mathrm{g}$ functionality) at $0.1 \mathrm{mmol}$ scale using $0.4 \mathrm{mmol}$ amino acid $/ 3 \mathrm{~mL}$ of DMF. Solid phase peptide synthesis (SPPS) was carried out on an automated peptide synthesis instrument (AAPTEC Focus XI). Deprotection reactions were performed using 20\% piperidine in DMF for $15 \mathrm{~min}$ and were repeated three times. Coupling reactions were carried out using $0.395 \mathrm{mmol} \mathrm{HBTU}$ and $2.5 \mathrm{~mL}$ of $0.4 \mathrm{M}$ NMM as activating agents for $1 \mathrm{~h}$. In addition to these agents, $0.44 \mathrm{mmol}$ HOBt was also used during the coupling of histidine and cysteine residues to prevent racemization. For each amino acid, double coupling cycles were performed. At the end of the synthesis, the resin was washed with DCM and dried under $\mathrm{N}_{2}$ flow at room temperature. Cleavage reactions 
were conducted using 92.5:5:2.5 TFA:DMB:TIS cocktail (20 mL cocktail/g resin) for $2.5 \mathrm{~h}$ [27]. The resin was filtered using a polypropylene column and the supernatant was precipitated over cold DEE with 1:10 cleavage cocktail: DEE volume ratio. The precipitate was washed with DEE and centrifuged. After evaporation of DEE under $\mathrm{N}_{2}$ flow at room temperature, the raw peptide was dissolved in $1 \mathrm{~mL} 1 \%$ acetic acid in deionized water, freeze dried and stored at $-20{ }^{\circ} \mathrm{C}$.

PEGylation of the raw peptide was carried out using Michael addition reaction involved in the mPEG-MAL and thiol group of cysteine at the N-terminus of the peptide (Fig. $\mathrm{S} 1)$. Approximately, $20 \mathrm{mg}$ peptide $(0.014 \mathrm{mmol})$ was dissolved in $10 \mathrm{~mL}$ PBS buffer under $\mathrm{N}_{2}$ gas flow for $10 \mathrm{~min}$ to prevent air oxidation of cysteines. $75 \mathrm{mg}$ mPEG-MAL $(0.015 \mathrm{mmol})$ was added under $\mathrm{N}_{2}$ blanketing and the reaction was allowed to proceed for $4 \mathrm{~h}$. Unreacted mPEG-MAL was separated using affinity chromatography with Ni-NTA resin which selectively binds to histidines of the peptide and mPEG-peptide conjugate. For the affinity chromatography, $50 \mathrm{mM}$ sodium phosphate containing $0.3 \mathrm{M} \mathrm{NaCl}$ at $\mathrm{pH} 8.0$ was used as binding and washing buffer. Unbound mPEGMAL was washed away until no PEG was detected in the solution according to the results of a colorimetric assay based on the complex formation of barium iodide and PEG [28]. The peptide and $\mathrm{mPEG}$-peptide were eluted from the resin using $50 \mathrm{mM}$ phosphate buffer containing $0.3 \mathrm{M} \mathrm{NaCl}$ and $0.5 \mathrm{M}$ imidazole at $\mathrm{pH}$ 7.4. To isolate mPEG-peptide conjugate, the peptide was removed by dialysis against deionized water using SnakeSkin dialysis tubing membrane with MWCO $3.5 \mathrm{kDa}$. Finally, the solution was freeze-dried, and mPEGAT1 conjugate was stored at $-20{ }^{\circ} \mathrm{C}$. Hydrazide form of mPEG-AT1 was obtained using the reaction between AADH and carboxylic acid group of glutamic acid residue at the Cterminus of the peptide. Same experimental procedures used to prepare $\mathrm{mPEG}-\mathrm{HYD}-\mathrm{DOX}$ were applied to obtain the final conjugate system, mPEG-AT1-DOX as given in Fig. S2 (Yield $=43 \pm 3 \%$ ).

\section{Characterization of the carrier molecules}

Hydrazide conjugation reaction with AADH was monitored by NMR spectroscopy. Approximately, $2.5 \mathrm{mg}$ sample was dissolved in $0.6 \mathrm{~mL} \mathrm{D}_{2} \mathrm{O}$ and ${ }^{1} \mathrm{H}$ NMR spectrum was taken using Varian Vnmr 400 model spectrometer. NMR data were analyzed using ACDLAB 12, 1D NMR Processor software. FTIR experiments were conducted using $\mathrm{KBr}$ pellet technique. Prior to analyses, moisture of the samples was removed/ reduced by keeping in a vacuum oven at room temperature for overnight. Approximately, $1 \mathrm{mg}$ sample was dispersed in $150 \mathrm{mg}$ potassium bromide to prepare a pellet. The spectra were taken between 400 and $4000 \mathrm{~cm}^{-1}$ by using Shimadzu IRPrestige-21 FTIR-8400S model spectrophotometer.
Purity of the peptide and mPEG-AT1 conjugate was assessed using reverse phase HPLC method with Agilent 1100 model HPLC system. $0.1 \%$ TFA in deionized water and $0.08 \%$ TFA in acetonitrile were used as Solvent A and Solvent B, respectively. $100 \mu \mathrm{L}$ filtered sample prepared in $0.1 \%$ TFA in water $(\sim 1-2 \mathrm{mg} / \mathrm{mL})$ was injected to $\mathrm{C} 18$ ana-

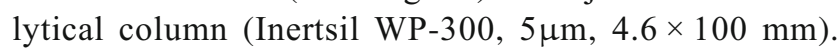
Solvent A:B ratio was changed from $95: 5$ to $30: 70$ within $65 \mathrm{~min}$ and the sample eluted from the column was monitored using a UV detector at $214 \mathrm{~nm}$. Analyses were carried out at $1 \mathrm{~mL} / \mathrm{min}$ solvent flow rate.

Molar mass of the peptide was determined using electrospray ionization mass spectroscopy (ESI-MS). The experiments were performed with an LTQ XL linear ion-trap mass spectrometer (Thermo Finnigan) equipped with an electrospray ionization source. The peptide sample was dissolved in $1 \%$ acetic acid in ultra-pure water and mixed with equal proportion of HPLC-grade methanol and infused directly into the mass spectrometer. Matrix-assisted laser desorption/ionization time of flight mass spectrometer (Bruker Daltonics-Autoflex III Smartbeam MALDI TOF/ TOF MS) was used for identification of the mPEG-peptide conjugate. The sample was dissolved in $0.1 \%$ TFA in ultrapure water and sinapic acid was used as a matrix.

\section{Characterization of the DOX conjugated drug delivery systems}

DOX conjugation percentages of the drug delivery systems (mPEG-HYD-DOX, and mPEG-AT1-DOX) were determined using Perkin Elmer Lambda-45 model UV-Vis spectroscopy. Approximately, $0.5 \mathrm{mg}$ conjugate was dissolved in $700 \mu \mathrm{L}$ deionized water. The exact concentration was recorded for the calculations. Absorbance value of the solution was determined at $488 \mathrm{~nm}$ and \% DOX functionalization values of the samples were calculated based on the extinction coefficient of free DOX, $11500 \mathrm{~L} \cdot \mathrm{mol}^{-1} \cdot \mathrm{cm}^{-1}[29]$.

Size distributions of the samples were obtained using Malvern ZetaSizer Nano ZS model instrument via dynamic light scattering technique. Diffusion coefficients of the samples were determined by applying CONTIN method and converted to hydrodynamic diameters via Stoke-Einstein equation provided by the software of the instrument. $3 \mathrm{mg} / \mathrm{mL}$ sample was dissolved in deionized water and diluted twofold using $20 \mathrm{mM}$ phosphate buffer containing $300 \mathrm{mM}$ $\mathrm{NaCl}$ at $\mathrm{pH} 7.4$ or $20 \mathrm{mM}$ acetate buffer containing $300 \mathrm{mM}$ $\mathrm{NaCl}$ at $\mathrm{pH} 5.0$ and filtered. Measurements were performed after equilibrating the cuvette for at least $5 \mathrm{~min}$ at $25^{\circ} \mathrm{C}$ and repeated three times. Size distributions of the samples were determined within a few hours after preparation of the solutions and after incubating the solutions for one day at $37{ }^{\circ} \mathrm{C}$.

Atomic force microscopy (AFM) observations were carried out on a Digital Instruments-MMSPM Nanoscope IV 
type of instrument. The sample, mPEG-AT1-DOX, was dissolved in deionized water and filtered. $2 \mu \mathrm{L}$ of the solution was pipetted onto a freshly cleaved mica plate and diluted using $8 \mu \mathrm{L}$ filtered deionized water. The plate was protected from light and air-dried. The image was taken in tapping mode using a silicon probe with a spring constant of $0.4 \mathrm{~N} / \mathrm{m}$ and resonance frequency of $70 \mathrm{kHz}$ (Bruker, Scanasyst-Air model). Height of the sample was determined using NanoScope Analysis software. Lateral dimensions and shape of the sample were analyzed using ImageJ software [30].

Drug release profiles of mPEG-HYD-DOX and mPEGAT1-DOX were obtained using dialysis procedure. $1.5 \mathrm{mg}$ sample dissolved in $1 \mathrm{~mL}$ buffer $(10 \mathrm{mM}$ acetate buffer containing $150 \mathrm{mM} \mathrm{NaCl}$ at $\mathrm{pH} 5.0$ or $10 \mathrm{mM}$ phosphate buffer containing $150 \mathrm{mM} \mathrm{NaCl}$ at $\mathrm{pH}$ 7.4) was placed in a dialysis membrane with a MWCO of $3.5 \mathrm{kDa}$. The membrane was transferred to a $50 \mathrm{~mL}$ Falcon tube containing $25 \mathrm{~mL}$ buffer solution and the lid of the tube was wrapped with parafilm to prevent evaporation. The tube was incubated at $37{ }^{\circ} \mathrm{C}$ by shaking at $150 \mathrm{rpm} .200 \mu \mathrm{L}$ of solution was withdrawn and replaced with the same volume of fresh buffer at certain time intervals $(1,3,6,10,24,48,56$, and $72 \mathrm{~h})$. Released DOX amount was determined using fluorescence emission intensity data at $590 \mathrm{~nm}$. Emission spectra were recorded between 400 and $700 \mathrm{~nm}$ with excitation wavelength of $480 \mathrm{~nm}$, excitation slit width of $5 \mathrm{~nm}$, emission slit width of $20 \mathrm{~nm}$ and scan rate of $125 \mathrm{~nm} / \mathrm{min}$. The experiments were performed on a Perkin Elmer LS55 model fluorescence spectrophotometer.

Cytotoxicity tests were carried out using MTT assay on human lung adenocarcinoma epithelial cell line (A549 cells). For a typical MTT assay, $90 \mu \mathrm{L}$ aliquots of the cells $\left(5 \times 10^{3}\right.$ cells/well) were seeded in a 96 well microplate (number of replicates $=4)$. Then, the cells were incubated at $37^{\circ} \mathrm{C}$ in $5 \%$ $\mathrm{CO}_{2}$ atmosphere for $24 \mathrm{~h}$. At the end of the incubation period, $10 \mu \mathrm{L}$ sample in sterile PBS buffer was added over the cells. The cells were incubated for another $24 \mathrm{~h}$ at the same conditions. The medium was discarded and changed with the fresh medium, then, incubated for another $24 \mathrm{~h}$ prior to application of MTT assay [20]. Next, $10 \mu \mathrm{L}$ MTT $(5 \mathrm{mg} / \mathrm{mL}$ in sterile PBS buffer) was added to the wells and the microplates were further incubated for $3 \mathrm{~h}$. After centrifuging at $1800 \mathrm{rpm}$ and at room temperature for $5 \mathrm{~min}$, the medium was carefully removed by a pipette and the microplate was inverted and blotted with a napkin. Next, $100 \mu \mathrm{L}$ DMSO was added and the microplates were shaken at $150 \mathrm{rpm}$ for $5 \mathrm{~min}$. Absorbance values were recorded at $570 \mathrm{~nm}$ with a reference wavelength of $690 \mathrm{~nm}$ using VarioSkan Flash Multimode Reader (Thermo Scientific). Absolute $\mathrm{IC}_{50}$ values of the samples were estimated as the concentration that corresponds to $50 \%$ cell viability using cubic spline interpolation method. Finally, independent 2-sample t-tests of the data were conducted using Minitab software. $p$-value less than 0.05 was considered to be statistically significant.

\section{Results and discussion}

\section{Synthesis of mPEG based carrier molecule}

In the first step of the preparation of the DOX-conjugated DDSs, hydrazide functionalized carrier molecules, $\mathrm{mPEG}$ and mPEGAT1 were synthesized using EDC and NHS activated carboxylic acid-hydrazide coupling reaction. Hydrazide functionalization of mPEG-COOH was monitored using FTIR spectroscopy, qualitatively. FTIR spectra of mPEG-COOH and mPEG-HYD are given in Fig. 2. In the FTIR spectrum of mPEG-COOH characteristic C-O stretching band of ether backbone was observed at $1110 \mathrm{~cm}^{-1}$. The bands around 1465 and $2885 \mathrm{~cm}^{-1}$ are due to the respective bending and stretching of $\mathrm{C}-\mathrm{H}$ groups. A weak band observed at $1727 \mathrm{~cm}^{-1}$ corresponds to carbonyl group. In the hydrazide functionalized sample, on the other hand, this band became undetectable. In addition to $\mathrm{C}-\mathrm{O}$ and $\mathrm{C}-\mathrm{H}$ group vibration bands observed mainly for mPEG-COOH, N-H bending band around $1655-1665 \mathrm{~cm}^{-1}$ appeared in the FTIR spectrum of mPEG-HYD suggesting the hydrazide functionalization reaction was successful.

To get quantitative information for hydrazide conjugation, ${ }^{1} \mathrm{H}$ NMR spectroscopy was used. ${ }^{1} \mathrm{H}$ NMR spectra of mPEG$\mathrm{COOH}, \mathrm{AADH}$ and mPEG-HYD samples in $\mathrm{D}_{2} \mathrm{O}$ are given in Fig. S3, Fig. S4 and Fig. 3, respectively. NMR spectrum of mPEG-COOH indicated a singlet at $3.31 \mathrm{ppm}$ and a large peak at $3.64 \mathrm{ppm}$ attributed to 3 protons of $\mathrm{CH}_{3}-\mathrm{O}$ (methoxy) groups and ether backbone protons $\left(\mathrm{O}-\mathrm{CH}_{2}-\mathrm{CH}_{2}\right)_{n}$, respectively. By comparing the area of these protons number average molecular weight $\left(\mathrm{M}_{\mathrm{n}}\right)$ of $\mathrm{mPEG}-\mathrm{COOH}$ was obtained as $\sim 5400 \mathrm{Da}$ ( spec value $=5000 \mathrm{Da}$ ). . Additionally, the chemical shift at $2.62 \mathrm{ppm}$ is due to 2 protons next to carboxylic acid group and using the area of this peak, percentage of $\mathrm{COOH}$ functional group was calculated as $88 \%$ (spect value $\geq 80 \%$ ).

Similar to the quantitative analysis of mPEG-COOH, number average molecular weight of $\mathrm{mPEG-HYD}$ was estimated as $5500 \mathrm{Da}$ close to that of the mPEG-COOH. This indicates that $M_{n}$ of the polymer did not change significantly during the hydrazide functionalization reaction and purification steps. Using

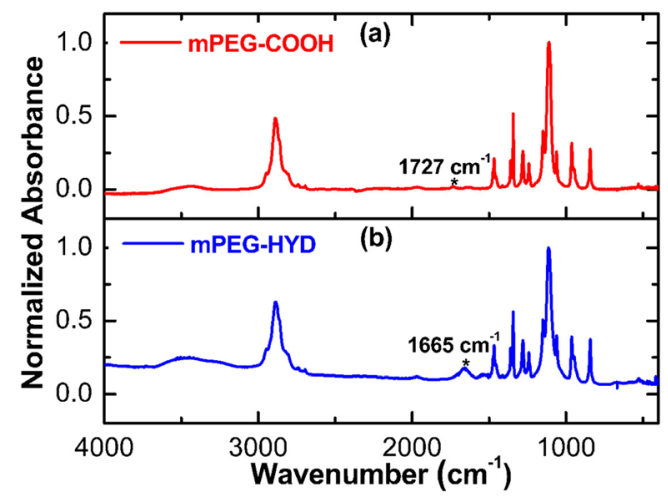

Fig. 2 FTIR spectra of (a) mPEG-COOH and (b) mPEG-HYD 


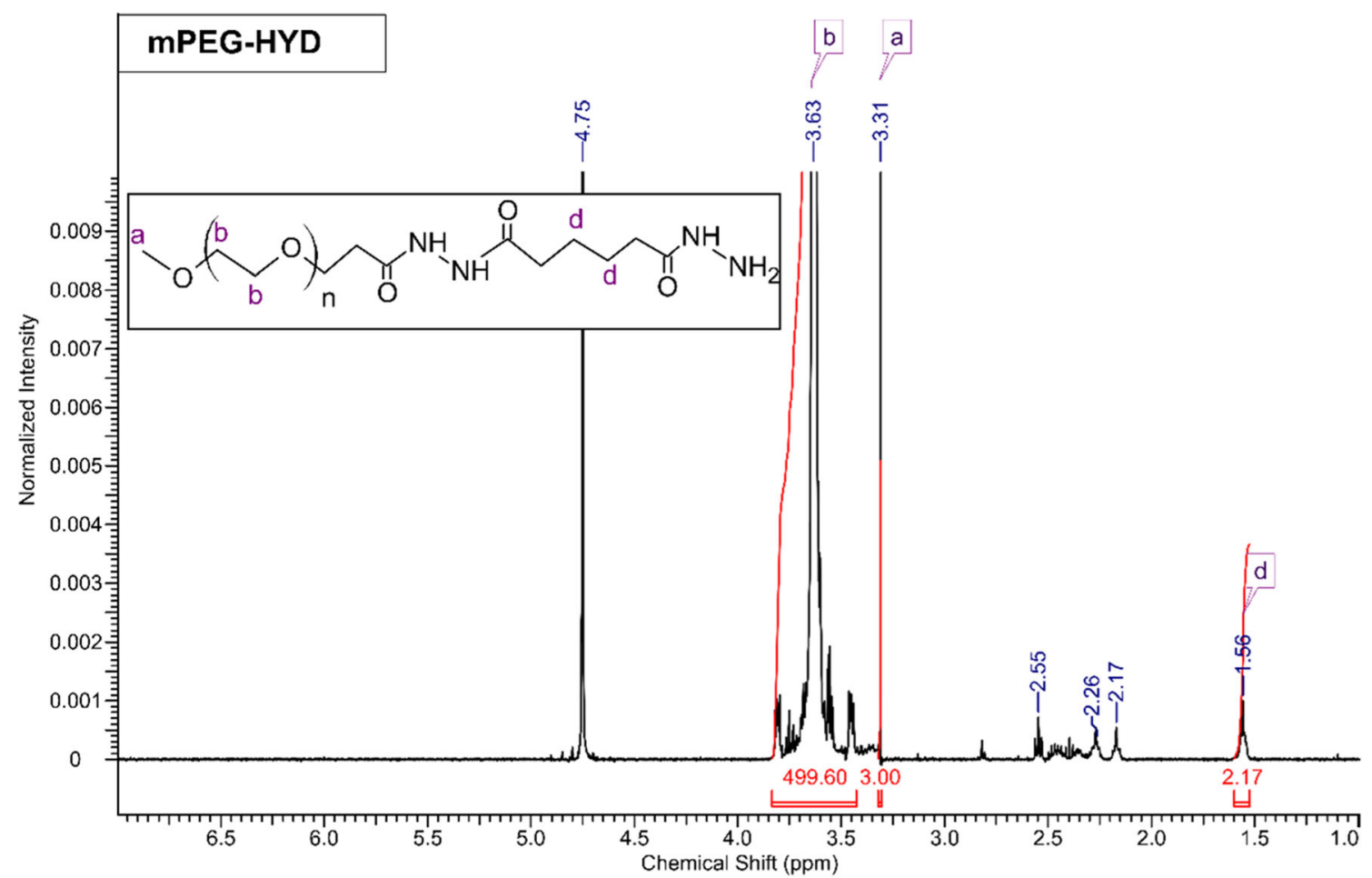

Fig. $3{ }^{1} \mathrm{H}$ NMR spectrum of mPEG-HYD in $\mathrm{D}_{2} \mathrm{O}$

the area of the chemical shift at $1.56 \mathrm{ppm}$ that corresponds to 4 protons, hydrazide conjugation percentage was estimated as $54 \%$. Comparing the $\mathrm{COOH}$ functionality of $\mathrm{mPEG}-$ propionic acid (88\%), it is apparent that not all $\mathrm{COOH}$ groups were replaced with hydrazide group.

Hydrazone bond is, perhaps, the mostly employed acid cleavable bond in the preparation of $\mathrm{pH}$ responsive drug delivery systems. In these systems, hydrazone bond forms as a result of the reaction between ketone group of a drug, mostly doxorubicin, and hydrazide group of any carrier molecule. Hydrazide groups have been introduced to drug delivery systems via different routes. For example, Etrych et al. (2001) obtained hydrazide functionalized N-(2-hydroxypropyl) methacrylamide (HPMA)-methacryloylglycyl-glycine 4nitrophenyl ester (Ma-Gly-Gly-ONp) random copolymers using the reaction between 4-nitrophenoxy (ONp) group and hydrazine monohydrate in methanol [31]. In another study, hydrazide groups were conjugated to aspartic acid side chains of mPEG-polyaspartate block copolymers in tertbutyloxycarbonyl (BOC) protected form via acid anhydride reaction in the presence of $\mathrm{N}$-methylmorpholine (NMM), isobutyl chloroformate (IBCF), carbazic acid tert-butyl ester (Cat-BE) and dimethyl acetamide (DMAc). BOC group was, then, removed using TFA to obtain hydrazide functionalized form of the block copolymer [20]. Hydrazide form of a PEG copolymer containing allyl groups was prepared using two consecutive reactions including the reaction with methyl mercaptoacetate in the presence of AIBN in THF followed by the reaction with hydrazine hydrate in THF [32].
Hermanson (1996), on the other hand, proposed a simple route performed in aqueous medium using EDC as a zero length crosslinker to couple carboxyl groups and primary amine group of a dihydrazide molecule forming an amine reactive o-acylisourea as an intermediate product [33]. It was reported that in the presence of water, yield of amide formation can be quite low because of fast hydrolysis rate of oacylisourea. Introduction of NHS, stabilizes this intermediate molecule and forms amine reactive NHS ester, which is more stable towards hydrolysis [34]. Thus, in this study, EDC and NHS ester were used to prepare hydrazide form of the carrier mPEG or mPEG-AT1 molecule. Hydrazide functionalization percentage of mPEG-HYD (54\%) was obtained to be lower than those obtained in organic solvents (> 75\%) [20, 31, 32]. Nevertheless, this value was enough to attach DOX molecules and to test the performance of the DOX-conjugated drug delivery systems.

\section{Synthesis of mPEG-peptide based carrier molecule}

The de novo peptide, AT1, was designed to exploit both ionization properties and reactive functional groups of amino acid side chains. The peptide sequence contains $\mathrm{C}, \mathrm{G}, \mathrm{H}$, and $\mathrm{E}$ residuals with the following assignments. At the $\mathrm{N}$ terminus of the peptide, cysteine (C) with thiol functional group served as $\mathrm{mPEG}$ conjugation site. Histidines $(\mathrm{H})$ were incorporated to provide $\mathrm{pH}$ responsiveness to the peptide as its $\mathrm{pK}_{\mathrm{a}}$ value is around 6.0. At the C-terminus, glutamic acid (E) having $\mathrm{COO}^{-}$group was used to attach DOX. Glycine 
(G) which is the smallest amino acid with a hydrogen atom in its side chain, was placed nearby $\mathrm{C}$ and $\mathrm{E}$ to minimize steric effects during the conjugation reactions.

Purity of AT1 peptide was assessed by ESI-MS and HPLC data given in Fig. S5 and Fig. 4, respectively. In the mass spectrum, theoretical molar mass of the peptide (1414 Da) was confirmed by the peaks corresponding to single and multiple charged peptide $\mathrm{m} / \mathrm{z}$ values. HPLC elution curve of the peptide presented a large peak around $24.9 \mathrm{~min}$ with relatively small peaks just next to this major peak (Fig. 4a). The presence of this highly pure fraction in the chromatogram along with the consistency of theoretical and experimental molar mass value of the peptide obtained from mass spectrum clearly indicated the peptide was synthesized at high purity.

Purity of the isolated mPEG-AT1 conjugate was evaluated by HPLC and MALDI-TOF mass spectroscopy. HPLC curves given in Fig. 4 indicated that AT1 peptide, mPEG-AT1 and mPEG-maleimide eluted in 24.9, 32.0 and $36.3 \mathrm{~min}$, respectively, in the order of increasing hydrophobicity. In the chromatogram of mPEG-AT1, no significant fractions corresponding to peptide or parent PEG molecule were observed suggesting mPEG-AT1 conjugate have high purity (Fig. 4c). MALDITOF analysis was conducted to determine molar mass of the conjugate. In the mass spectrum of the conjugate a peak was observed at $\sim 6600 \mathrm{Da}$ (Fig. S6), which is close to its theoretical molar mass confirming that the conjugation reaction was successful.

Further evidence of the PEGylation of the peptide was also provided by comparing the fingerprints of the peptide, mPEG-MAL, and the conjugate in their FTIR spectra as given in Fig. 5. It is quite clear that the conjugate have a FTIR pattern matching to both parent molecules. More specifically, the band around $2900 \mathrm{~cm}^{-1}$ assigned to $\mathrm{C}-\mathrm{H}$ stretching of PEG backbone appears in the FTIR spectra of both the PEG and the conjugate. Similarly, amide I and amide II bands of the peptide in $1500-1700 \mathrm{~cm}^{-1}$ region were also observed in the spectrum of the conjugate. Thus, these three characterization methods confirmed that high purity of mPEG-peptide conjugate was isolated.

\section{Characterization of the DOX conjugated drug delivery systems}

$\%$ of DOX conjugation values of mPEG-HYD-DOX and mPEG-AT1-DOX were obtained as $62 \pm 7 \%$ and $35 \pm 3 \%$, respectively. For mPEG-HYD-DOX, DOX conjugation percentage obtained seemed slightly higher than hydrazide functionalization $(\sim 54 \%)$. This can be attributed remaining free DOX in the conjugates that could not be separated during GPC. In the purification of the conjugates, a clear color difference was apparent in the elution fractions of GPC (conjugates = red, free DOX $=$ orange) suggesting most of the free DOX was separated. Nevertheless, standard deviation values of \% DOX

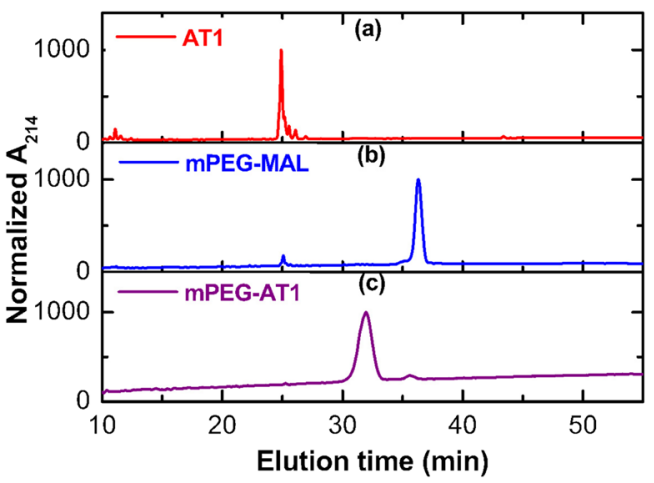

Fig. 4 HPLC curves of (a) AT1, (b) mPEG-MAL, and (c) mPEG-AT1

conjugations indicate the difference between hydrazide conjugation $\%$ and DOX conjugation $\%$ are within experimental error. DOX conjugation $\%$ of the mPEG-peptide based DDS was obtained to be lower than that of the MPEG based DDS. The possible reason can be increased steric hindrance effect of the more crowded environment nearby the drug conjugation site in the case of the mPEG-peptide DDS.

Dynamic light scattering was used to determine aggregation state and stability of the DOX-conjugated DDSs. Figure 6 shows size (hydrodynamic diameter) distributions of mPEG$\mathrm{COOH}$ and mPEG-HYD in PBS buffer (pH 7.4) and mPEGAT1 in both PBS buffer at $\mathrm{pH} 7.4$ and acetate buffer at $\mathrm{pH}$ 5.0. Average size of the samples was determined to be similar for all of the samples with a value around $4 \pm 0.5 \mathrm{~nm}$. It was also observed that $\mathrm{pH}$ change did not affect the size of mPEG-AT1.

It is possible to predict hydrodynamic diameter $\left(\mathrm{D}_{\mathrm{H}}\right)$ of PEG in $\AA$ as a function of its molar mass $\left(\mathrm{M}_{\mathrm{n}}\right)$ in Da via the following correlation [35]:

$\mathrm{D}_{\mathrm{H}}=0.3824 \mathrm{M}_{\mathrm{n}}^{0.559}$

The equation above gave size of a PEG molecule with a molar mass of $5000 \mathrm{Da}$ as $\sim 4.4 \mathrm{~nm}$, which is consistent with the experimental values. Thus, it can be concluded that neither functionalized mPEG molecules nor mPEG-AT1 conjugate has aggregation tendency.

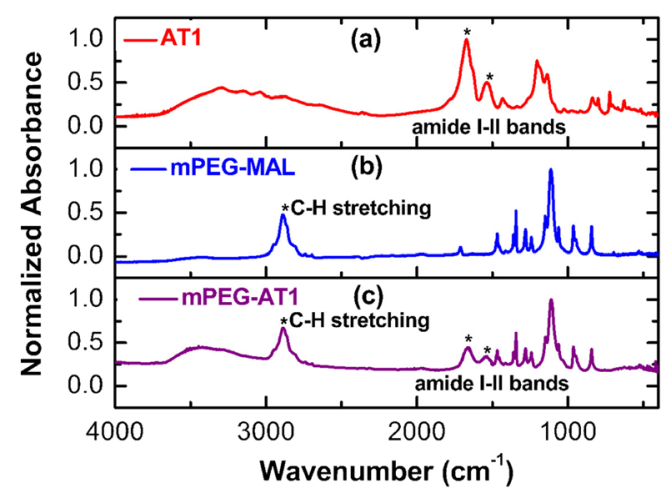

Fig. 5 FTIR spectra of (a) AT1, (b) mPEG-MAL, and (c) mPEG-AT1 


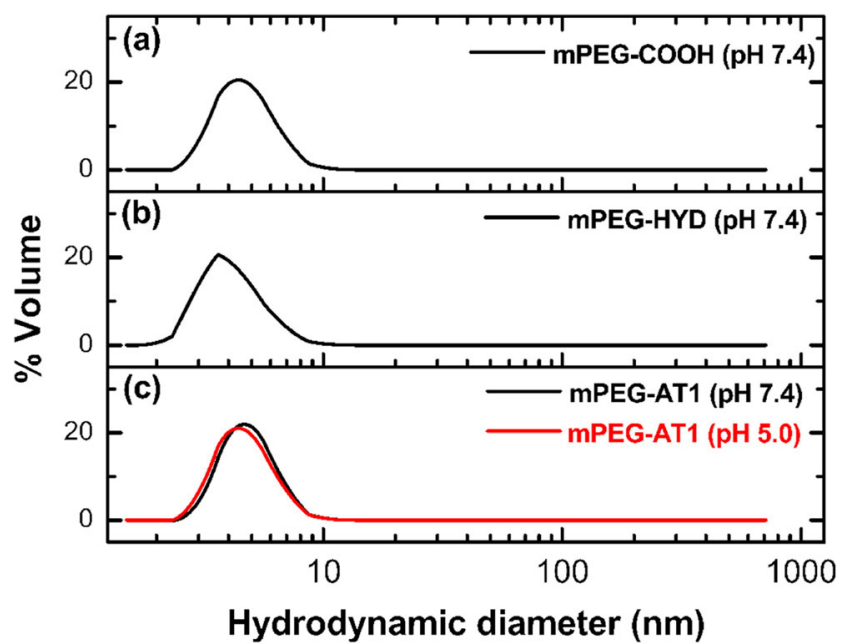

Fig. 6 Size distributions of mPEG molecules with different functional groups and mPEG-AT1 conjugate

Size distributions of the DOX-conjugated DDSs followed completely different patterns. Results of the measurements taken within a few hours after the dissolution of the conjugates in appropriate buffer and after incubating the solution at $37^{\circ} \mathrm{C}$ for 1 day are given in Figs. 7 and 8, respectively. Average sizes of mPEG-HYD-DOX at $\mathrm{pH} 7.4$ and $\mathrm{pH} 5.0$ upon immediate measurement were obtained as about $9 \pm 0.5 \mathrm{~nm}$ and $7 \pm 0.5 \mathrm{~nm}$, respectively. Aggregated structures of mPEG-HYD-DOX were observed to be stable with at most a few nm reduction in the average size after $24 \mathrm{~h}$ incubation period independent of $\mathrm{pH}$. Average size of the conjugate at $\mathrm{pH} 7.4$ is about twice of that of mPEG-HYD molecule. Thus, it can be suggested that the drug conjugation to the carrier molecule, mPEG-HYD, triggered self-assembly of the DOX-conjugated DDS resulting micellar aggregates, in which drug molecules are in the core and hydrophilic PEG molecules are at the surface. Conjugation of DOX to PEG-peptide conjugates containing enzymatically degradable units has also been resulted in the formation of aggregated structures with aggregation number dictated by architecture and molecular weight of PEG molecules [36]. The two pKa values of doxorubicin have been reported as 8.2 and 9.5 [37]. Below

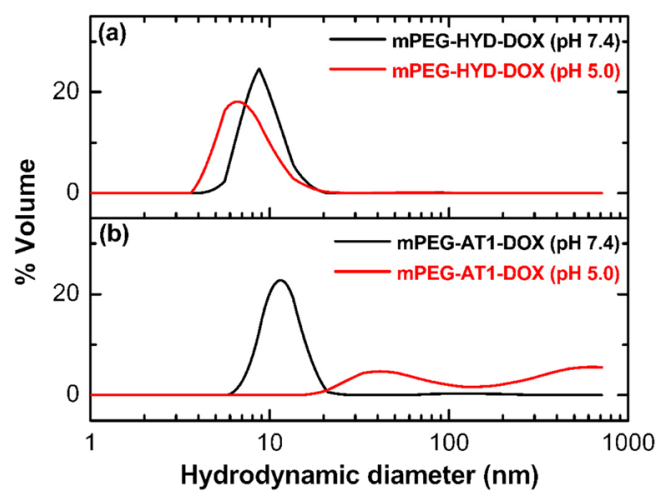

Fig. 7 Size distributions of the as prepared DOX-conjugated DDSs

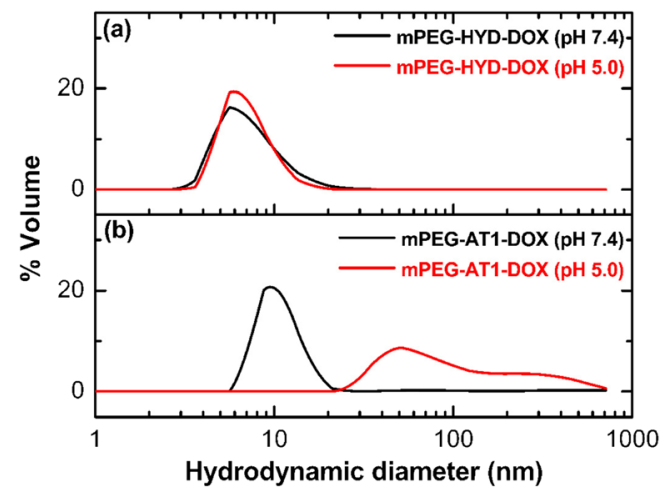

Fig. 8 Size distributions of the DOX-conjugated DDSs obtained after $24 \mathrm{~h}$ incubation at $37^{\circ} \mathrm{C}$

$\mathrm{pH}$ 8.2, aglycone part is neutral whereas amine group of the daunosamine is protonated $[37,38]$. However, various experimental techniques including NMR, absorption, florescence, and mass spectroscopy, viscosity, and permeation measurements confirmed that charge repulsions can be eliminated by the addition of salt and suppressed by attraction forces causing self-association (dimerization below $5 \mathrm{mM}$ concentration) of doxorubicin [37-41]. Viscosity measurements also showed no change in aggregation state between $\mathrm{pH} 7.5$ and 5 [40]. Hence, aggregate structure of the drug delivery systems was stabilized mainly by $\pi-\pi$ stacking and hydrophobic interactions between doxorubicin molecules, as expected [39, 42].

mPEG-peptide based DDS, mPEG-AT1-DOX, have similar type of chemical bond between the carrier and drug molecule as in mPEG-HYD. However, different from this mPEG (only)-based DDS, mPEG-AT1-DOX also contains pH responsive peptide domain. Therefore, the role of the peptide domain in the DOX-conjugated DDS can be elucidated by comparing its size distribution data with those of mPEGHYD-DOX. At $\mathrm{pH} 7.4$, slightly larger average size $(\sim 12 \pm$ $2 \mathrm{~nm}$ ) was obtained for mPEG-AT1-DOX. Considering the size of the aggregates is slightly higher than twice of the size of the parent molecule, mPEG-AT1, it can deduced that likewise mPEG-HYD-DOX, mPEG-AT1-DOX also formed aggregated structures. At $\mathrm{pH} 5$, on the other hand, larger aggregate sizes ranging from 20 to $100 \mathrm{~nm}$ centered around $40 \mathrm{~nm}$ were obtained for mPEG-AT1-DOX. Similarly, mean size of PEG-poly(histidine) and PEG-poly(L-lactide) mixed micelles measured as $129 \pm 10 \mathrm{~nm}$ at $\mathrm{pH} 7.4$ was reported to gradually increase as $\mathrm{pH}$ decreased $(232 \pm 25 \mathrm{~nm}$ at $\mathrm{pH}$ 6.5) [43]. Thus, it is likely that the repulsions between positively charged histidines at $\mathrm{pH} 5.0$ prevented close packing of the molecules and drove the molecules to form loosely packed and more hydrated structures with higher mean hydrodynamic diameter. No significant change in the stability of mPEG-AT1-DOX aggregates was observed at neutral $\mathrm{pH}$. However, approximately $10 \mathrm{~nm}$ nanometer increase in its mean size upon was obtained upon incubation of mPEG-AT1-DOX in pH 5.0 buffer at $37^{\circ} \mathrm{C}$ for $24 \mathrm{~h}$. 


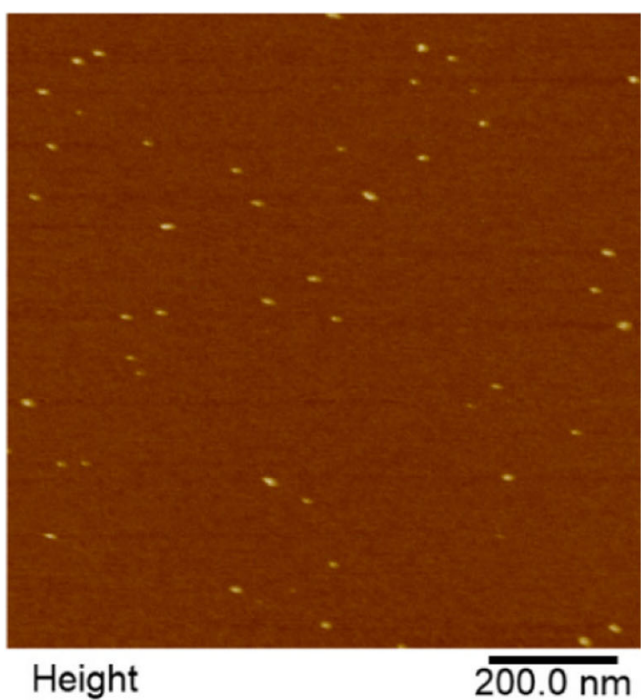

(a)

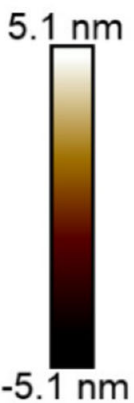

$-5.1 \mathrm{~nm}$

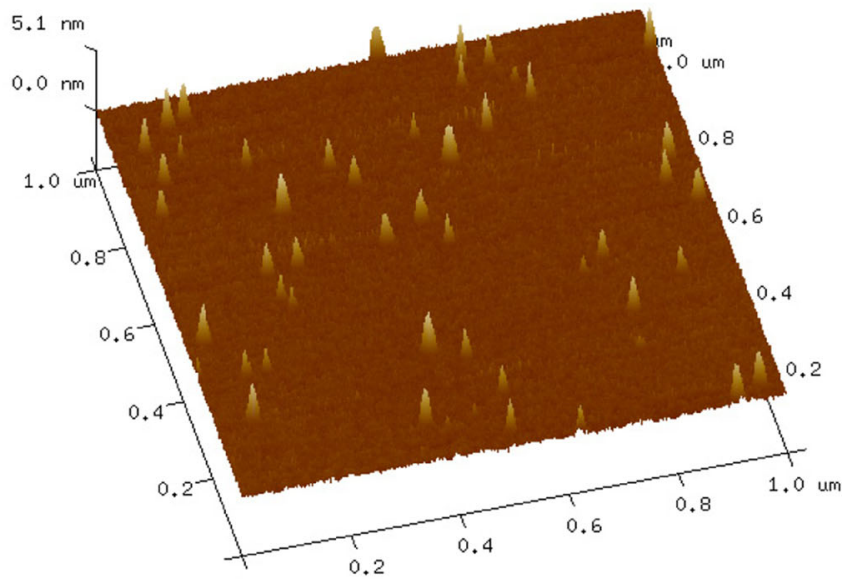

(b)

Fig. 9 a 2D and (b) 3D AFM images of mPEG-AT1-DOX

Morphology of mPEG-AT1-DOX structures was observed using AFM. 2D and 3D AFM images of the sample are given in Fig. 9. Elongated structures with an average aspect ratio of $2.0 \pm 0.4$ were obtained. Heights of the structures were measured as between 2.3 and $3.7 \mathrm{~nm}$ with an average value of $\sim 2.9 \mathrm{~nm}$. This value corresponds to the diameter of the collapsed aggregate in dried state where PEG chains are no longer extended and hydrated state and hence the height measured mostly describes the size of the hydrophobic core of the aggregate [44]. Feret diameter and minimum caliper diameter of the core of the aggregates were measured as $18.8 \pm 4.8 \mathrm{~nm}$ and $9.2 \pm 2.7 \mathrm{~nm}$, higher than expected, due to tip broadening effect which limits the resolution of lateral dimensions of the structures in AFM.

DOX release profiles of $\mathrm{mPEG}-\mathrm{HYD}-\mathrm{DOX}$ and $\mathrm{mPEG}-$ AT1-DOX at $\mathrm{pH} 7.4$ and $\mathrm{pH} 5.0$ are given in Fig. 10. At the end of $72 \mathrm{~h}, \%$ DOX release values of mPEG-HYD-DOX were obtained as $8 \pm 1 \%$ and $12 \pm 2 \%$ at $\mathrm{pH} 7.4$ and at $\mathrm{pH}$ 5.0, respectively. These results indicated that mPEGHYD-DOX have slight $\mathrm{pH}$ responsive drug release behavior. mPEG-AT1-DOX presented faster DOX release at $\mathrm{pH} 5(30 \pm$ $7 \%)$ compared to $\mathrm{pH} 7.4(14.5 \pm 2.5 \%)$ and, hence, more pronounced $\mathrm{pH}$ programmed release behavior compared to the mPEG-only DDS. It is likely that addition of histidines into the drug delivery system increased DOX release at acidic $\mathrm{pH}$ due to decreased attractions between aggregated structures of mPEG-AT1-DOX thereby facilitating contact of the solvent molecules with the acid cleavable hydrazone bonds. Comparison of the other DDS systems suggested that the release behavior of mPEG-HYD is similar to mPEG-PLLAHYD-DOX system where single DOX was attached to the carrier amphiphilic molecule which has inherent tendency to form compact aggregates with a size of $89 \pm 12 \mathrm{~nm}$. For
mPEG-PLLA-HYD-DOX, \% DOX release values were reported as 20 and $24 \%$ at the end of $25 \mathrm{~h}$ at pH 5.0 and $\mathrm{pH} 7.4$, respectively [45]. $\mathrm{pH}$ responsiveness was observed to be more apparent for multivalent mPEG-polyaspartateHYD-DOX drug delivery system having mean aggregate size of $65 \mathrm{~nm}$ as revealed by no release at all at neutral $\mathrm{pH}$. At $\mathrm{pH} 5.0$, on the other hand, \% DOX release was obtained as $28 \%$ at the end of $72 \mathrm{~h}$ [20]. PEO-g-HYD-DOX system with a size of 9-11 nm exhibited much higher DOX release rate ( $90 \%$ at $\mathrm{pH} 5.0$ at the end of $72 \mathrm{~h}$ ) than that of the drug delivery systems that are forming larger aggregates [32]. Considering the correlation between aggregation behavior of drug delivery systems and their drug release abilities, mPEG-AT1-DOX would be expected to release higher amount of DOX at acidic $\mathrm{pH}$. As revealed by the size of the mPEG-AT1-DOX, the number of charged histidines in the peptide seemed not enough to completely destabilize the aggregates. Thus, it can

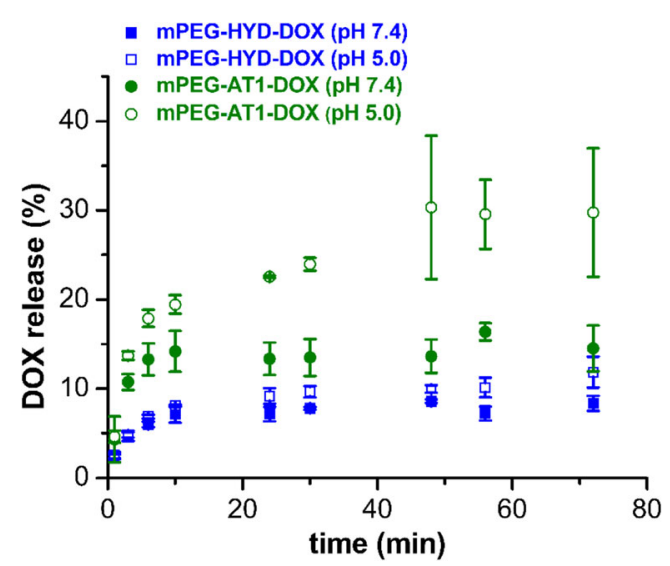

Fig. 10 DOX release curves of mPEG-HYD-DOX and mPEG-AT1DOX at $\mathrm{pH} 7.4$ and $\mathrm{pH} 5.0$ 


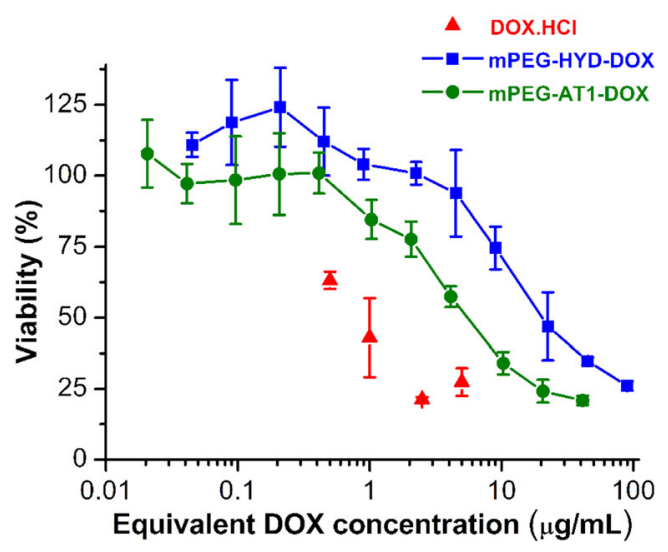

Fig. 11 Dose dependent cytotoxicity results of free DOX and DOXconjugated DDSs

be speculated that incorporation of more histidines to the peptide block of the carrier molecule can be resulted in higher $\mathrm{pH}$ sensitivity and, hence, faster DOX release.

Cytotoxicity results of mPEG-COOH, AADH, mPEGHYD and AT1 peptide are given in Fig. S7. No significant cytotoxicity of these samples was revealed. Growth inhibition curves of free DOX and the DOX-conjugated DDSs are given in Fig. 11. The resultant DOX equivalent $\mathrm{IC}_{50}$ values were obtained as $0.96 \pm 0.51,21.9 \pm 5.9$, and $5.55 \pm 0.75 \mu \mathrm{g} / \mathrm{mL}$ for free DOX, mPEG-HYD-DOX, and mPEG-AT1-DOX, respectively. Statistical analysis revealed that all $p$-values for the $\mathrm{IC}_{50}$ values of free DOX, mPEG-HYD-DOX, and mPEG-AT1DOX pairs were obtained to be less than 0.05 indicating statistically significant differences between the cytotoxicity of the samples (Table S1). DOX-conjugated DDSs exhibited higher $\mathrm{IC}_{50}$ value than free DOX. It was reported that biodegradable block copolymer doxorubicin conjugates and a peptidedoxorubicin conjugate where DOX was attached to the carrier molecule via an acid cleavable bond exhibited cytotoxicity lower than that of free DOX for A549 cell-line as free DOX molecules are more readily internalized and transported to nucleus with a faster rate $[46,47]$. Of the DOX-conjugated systems developed in current study, mPEG-AT1-DOX presented higher toxicity. Histidine-rich peptides and polypeptides have been shown to act as endosomal escape facilitator due to proton sponge effect $[48,49]$. Considering no significant toxicity of AT1, the superior cytotoxicity of mPEG-AT1-DOX can be attributed to its more pronounced $\mathrm{pH}$ responsive property and possible endosome disruption ability.

\section{Conclusions}

pH sensitive DOX-conjugated drug delivery systems based on mPEG (mPEG-HYD-DOX) and mPEG-peptide (mPEGAT1-DOX) were synthesized. DOX was attached to both DDSs via acid cleavable hydrazone bond. The peptide,
AT1, was designed to have a hexa-histidine domain to impart additional $\mathrm{pH}$ sensitivity to the DDS. Both DDSs formed aggregated structures upon DOX conjugation. Compared to mPEG-HYD-DOX, mPEG-AT1-DOX exhibited more pronounced $\mathrm{pH}$ responsiveness as indicated by its $\%$ DOX release performance at $\mathrm{pH} 5.0$ and $\mathrm{pH}$ 7.4. $\mathrm{IC}_{50}$ values were obtained in increasing order of free DOX $<$ mPEG-AT1-DOX < mPEG-HYD-DOX.

Superior drug release properties and cytotoxicity of mPEG-AT1-DOX compared to those of mPEG-HYDDOX conjugate system suggested the conjugates containing both $\mathrm{pH}$ sensitive domains and chemical bonds could be promising drug delivery systems. However, to exploit enhanced permeability and retention (EPR) effect, larger size of the DOX-conjugated carrier molecule should be required. Such a system may be possible by the development of a multivalent system where a number of drug molecules can be attached or by decreasing the length of the hydrophilic PEG block. Additionally, $\mathrm{pH}$ sensitivity of the DDS can be improved by the incorporation of more histidines to the peptide domain.

Acknowledgements The work was financially supported by The Scientific and Technological Research Council of Turkey (TÜBİTAK) [grant number 112S554]. İzmir Institute of Technology Biotechnology and Bioengineering Research and Application Center and Research Specialist Özgür Y1lmazer are acknowledged for making cytotoxicity tests possible. We thank to Materials Research Center at İzmir Institute of Technology and Research Specialist Mine Bahçeci for AFM experiments. We also thank to Prof. Talat Yalçın and Dr. Ahmet Emin Atik for kindly providing mass spectroscopy data, which were taken at Biological Mass Spectrometry and Proteomics Facility at İzmir Institute of Technology.

\section{References}

1. Lee ES, Na K, Bae YH (2005) Doxorubicin loaded pH-sensitive polymeric micelles for reversal of resistant MCF-7 tumor. J Control Release 103:405-418

2. Xu P, Van Kirk EA, Murdoch WJ, Zhan Y, Isaak DD, Radosz M, Shen Y (2006) Anticancer efficacies of cisplatin-releasing pH-responsive nanoparticles. Biomacromolecules 7:829-835

3. Ganta S, Devalapally H, Shahiwala A, Amiji M (2008) A review of stimuli-responsive nanocarriers for drug and gene delivery. J Control Release 126:187-204

4. Ulbrich K, Šubr VR (2004) Polymeric anticancer drugs with pHcontrolled activation. Adv Drug Deliv Rev 56:1023-1050

5. Kanamala M, Wilson WR, Yang M, Palmer BD, Wu Z (2016) Mechanisms and biomaterials in $\mathrm{pH}$-responsive tumour targeted drug delivery: a review. Biomaterials 85:152-167

6. Lee ES, Gao Z, Bae YH (2008) Recent progress in tumor $\mathrm{pH}$ targeting nanotechnology. J Control Release 132:164-170

7. Yin Q, Shen J, Zhang Z, Yu H, Li Y (2013) Reversal of multidrug resistance by stimuli-responsive drug delivery systems for therapy of tumor. Adv Drug Deliv Rev 65:1699-1715

8. Shenoy D, Little S, Langer R, Amiji M (2005) Poly(ethylene oxide)-modified poly( $\beta$-amino ester) nanoparticles as a $\mathrm{pH}$-sensitive 
system for tumor-targeted delivery of hydrophobic drugs. 1. In vitro evaluations. Mol Pharm 2:357-366

9. Simon SM (1999) Role of organelle pH in tumor cell biology and drug resistance. Drug Discov Today 4:32-38

10. Johnson RP, John JV, Kim I (2014) Poly(L-histidine)-containing polymer bioconjugate hybrid materials as stimuli-responsive theranostic systems. J Appl Polym Sci 131:40796

11. Lee ES, Shin HJ, Na K, Bae YH (2003) Poly (L-histidine)-PEG block copolymer micelles and $\mathrm{pH}$-induced destabilization. J Control Release 90:363-374

12. Oh KT, Lee ES, Kim D, Bae YH (2008) L-histidine-based pHsensitive anticancer drug carrier micelle: reconstitution and brief evaluation of its systemic toxicity. Int J Pharm 358:177-183

13. Min KH, Kim J-H, Bae SM, Shin H, Kim MS, Park S, Lee H, Park R-W, Kim I-S, Kim K (2010) Tumoral acidic pH-responsive MPEG-poly ( $\beta$-amino ester) polymeric micelles for cancer targeting therapy. J Control Release 144:259-266

14. Wang L, Liu G, Wang X, Hu J, Zhang G, Liu S (2015) Aciddisintegratable polymersomes of $\mathrm{pH}$-responsive amphiphilic diblock copolymers for intracellular drug delivery. Macromolecules 48:7262-7272

15. Wang Y, Chang B, Yang W (2012) pH-sensitive polyketal nanoparticles for drug delivery. J Nanosci Nanotechnol 12:8266-8275

16. Heffernan MJ, Murthy N (2005) Polyketal nanoparticles: a new pHsensitive biodegradable drug delivery vehicle. Bioconjug Chem 16: 1340-1342

17. Gillies ER, Fréchet JM (2005) pH-responsive copolymer assemblies for controlled release of doxorubicin. Bioconjug Chem 16: 361-368

18. Huang D, Yang F, Wang X, Shen H, You Y, Wu D (2016) Facile synthesis and self-assembly behaviour of $\mathrm{pH}$-responsive degradable polyacetal dendrimers. Polym Chem 7:6154-6158

19. Gu L, Wang N, Nusblat LM, Soskind R, Roth CM, Uhrich KE (2017) $\mathrm{pH}$-responsive amphiphilic macromolecular carrier for doxorubicin delivery. J Bioact Compat Polym 32:3-16

20. Bae Y, Fukushima S, Harada A, Kataoka K (2003) Design of environment-sensitive supramolecular assemblies for intracellular drug delivery: polymeric micelles that are responsive to intracellular $\mathrm{pH}$ change. Angew Chem Int Ed 115:4788-4791

21. Rihová B, Etrych T, Pechar M, Jelınková M, Štastný M, Hovorka O, Kovár M, Ulbrich K (2001) Doxorubicin bound to a HPMA copolymer carrier through hydrazone bond is effective also in a cancer cell line with a limited content of lysosomes. J Control Release 74:225-232

22. Ulbrich K, Etrych T, Chytil P, Jelinkova M, Říhová B (2004) Antibody-targeted polymer-doxorubicin conjugates with $\mathrm{pH}$ controlled activation. J Drug Target 12:477-489

23. Dong DW, Tong SW, Qi XR (2013) Comparative studies of polyethylenimine-doxorubicin conjugates with $\mathrm{pH}$-sensitive and pH-insensitive linkers. J Biomed Mater Res A 101:1336-1344

24. Guo X, Shi C, Wang J, Di S, Zhou S (2013) pH-triggered intracellular release from actively targeting polymer micelles. Biomaterials 34:4544-4554

25. Gillies ER, Goodwin AP, Fréchet JM (2004) Acetals as pHsensitive linkages for drug delivery. Bioconjug Chem 15:12541263

26. Hudecz F, Ross H, Price MR, Baldwin RW (1989) Immunoconjugate design: a predictive approach for coupling of daunomycin to monoclonal antibodies. Bioconjug Chem 1:197204

27. Stathopoulos P, Papas S, Tsikaris V (2006) C-terminal N-alkylated peptide amides resulting from the linker decomposition of the rink amide resin. A new cleavage mixture prevents their formation. J Pept Sci 12:227-232
28. Gong XW, Wei DZ, He ML, Xiong YC (2007) Discarded free PEG-based assay for obtaining the modification extent of pegylated proteins. Talanta 71:381-384

29. Etrych T, Chytil P, Jelínková M, Ř́hová B, Ulbrich K (2002) Synthesis of HPMA copolymers containing doxorubicin bound via a hydrazone linkage. Effect of spacer on drug release and in vitro cytotoxicity. Macromol Biosci 2:43-52

30. Schneider CA, Rasband WS, Eliceiri KW (2012) NIH image to image J: 25 years of image analysis. Nat Methods 9:671-675

31. Etrych T, Jelínková M, Ř́hová B, Ulbrich K (2001) New HPMA copolymers containing doxorubicin bound via $\mathrm{pH}$-sensitive linkage: synthesis and preliminary in vitro and in vivo biological properties. J Control Release 73:89-102

32. Zhou L, Cheng R, Tao H, Ma S, Guo W, Meng F, Liu H, Liu Z, Zhong Z (2011) Endosomal pH-activatable poly(ethylene oxide)graft-doxorubicin prodrugs: synthesis, drug release, and biodistribution in tumor-bearing mice. Biomacromolecules 12: $1460-1467$

33. Hermanson GT (1996) Bioconjugate Techniques. Academic Press, San Diego

34. Conde J, Dias JT, Grazú V, Moros M, Baptista PV, Jesus M (2014) Revisiting 30 years of biofunctionalization and surface chemistry of inorganic nanoparticles for nanomedicine. Front Chem 2:48

35. Fee CJ, Van Alstine JM (2006) PEG-proteins: reaction engineering and separation issues. Chem Eng Sci 61:924-939

36. Veronese FM, Schiavon O, Pasut G, Mendichi R, Andersson L, Tsirk A, Ford J, Wu G, Kneller S, Davies J (2005) PEGdoxorubicin conjugates: influence of polymer structure on drug release, in vitro cytotoxicity, biodistribution, and antitumor activity. Bioconjug Chem 16:775-784

37. Fülöp Z, Gref R, Loftsson T (2013) A permeation method for detection of self-aggregation of doxorubicin in aqueous environment. Int J Pharm 454:559-561

38. Anand R, Ottani S, Manoli F, Manet I, Monti S (2012) A close-up on doxorubicin binding to $\gamma$-cyclodextrin: an elucidating spectroscopic, photophysical and conformational study. RSC Adv 2:23462357

39. Agrawal P, Barthwal SK, Barthwal R (2009) Studies on selfaggregation of anthracycline drugs by restrained molecular dynamics approach using nuclear magnetic resonance spectroscopy supported by absorption, fluorescence, diffusion ordered spectroscopy and mass spectrometry. Eur J Med Chem 44:1437-1451

40. Hayakawa E, Furuyo K, Kuroda T, Moriyama M, Kondo A (1991) Viscosity study on the self-association of doxorubicin in aqueous solution. Chem Pharm Bull 39:1282-1286

41. Menozzi M, Valentini L, Vannini E, Arcamone F (1984) Selfassociation of doxorubicin and related compounds in aqueous solution. J Pharm Sci 73:766-770

42. Wang X, Wu G, Lu C, Zhao W, Wang Y, Fan Y, Gao H, Ma J (2012) A novel delivery system of doxorubicin with high load and $\mathrm{pH}-$ responsive release from the nanoparticles of poly $(\alpha, \beta$-aspartic acid) derivative. Eur J Pharm Sci 47:256-264

43. Yin H, Lee ES, Kim D, Lee KH, Oh KT, Bae YH (2008) Physicochemical characteristics of $\mathrm{pH}$-sensitive poly (L-histidine)-b-poly (ethylene glycol)/poly (L-lactide)-b-poly (ethylene glycol) mixed micelles. J Control Release 126:130-138

44. Hong G, Zou Y, Antaris AL, Diao S, Wu D, Cheng K, Zhang X, Chen C, Liu B, He Y (2014) Ultra-fast fluorescence imaging in vivo with conjugated polymer fluorophores in the second near-infrared window. Nat Commun 5:4206

45. Yoo HS, Lee EA, Park TG (2002) Doxorubicin-conjugated biodegradable polymeric micelles having acid-cleavable linkages. J Control Release 82:17-27

46. Hu X, Liu S, Huang Y, Chen X, Jing X (2010) Biodegradable block copolymer-doxorubicin conjugates via different linkages: 
preparation, characterization, and in vitro evaluation. Biomacromolecules 11:2094-2102

47. Jin Y, Huang Y, Yang H, Liu G, Zhao R (2015) A peptide-based $\mathrm{pH}$-sensitive drug delivery system for targeted ablation of cancer cells. Chem Commun 51:14454-14457

48. Meng Z, Luan L, Kang Z, Feng S, Meng Q, Liu K (2017) Histidineenriched multifunctional peptide vectors with enhanced cellular uptake and endosomal escape for gene delivery. J Mater Chem B 5:74-84

49. Midoux P, Pichon C, Yaouanc JJ, Jaffrès PA (2009) Chemical vectors for gene delivery: a current review on polymers, peptides and lipids containing histidine or imidazole as nucleic acids carriers. $\mathrm{Br}$ J Pharmacol 157:166-178 